chronic obstructive pulmonary disease. Am J Respir Crit Care Med 1998; 157:1418-22

4. Paggiaro PL, Dahle R, Bakran I, Frith L, Hollingworth K, Efthimiou J. Multicentre randomised placebo-controlled trial of inhaled fluticasone propionate in patients with chronic obstructive pulmonary disease. Lancet 1998;351:773-80. [Erratum, Lancet 1998;351:1968.]

\section{Risk Factors for Cerebral Edema in Children with Diabetic Ketoacidosis}

To the Editor: The study by Glaser et al. (Jan. 25 issue) ${ }^{1}$ identified risk factors for the development of symptomatic cerebral edema in children with diabetic ketoacidosis. Of the 61 children in whom symptomatic cerebral edema developed, 57 percent recovered completely, 21 percent had permanent neurologic damage, and 21 percent died. The investigators did not identify the risk factors for death from cerebral herniation or for permanent neurologic damage. It would be clinically relevant to compare the children who died or had permanent neurologic damage with those who did not have symptomatic cerebral edema or who had symptomatic cerebral edema but recovered completely.

The authors conclude that the rate of fluid administration and the tonicity of the fluid that was administered, when analyzed separately, were not related to the risk of cerebral edema. However, they did not evaluate whether the use of hypotonic fluid, when administered at a high rate, was a risk factor for cerebral edema. It is possible that both of these factors are necessary to increase the risk of cerebral edema. Finally, the authors identified three children who had cerebral edema before the initiation of therapy. Did these children receive excessive oral rehydration with hypotonic fluid (such as water) at home, before their presentation at the hospital?

\author{
Bassam M. Gebara, M.D. \\ William Beaumont Hospital \\ Royal Oak, MI 48073
}

1. Glaser N, Barnett P, McCaslin I, et al. Risk factors for cerebral edema in children with diabetic ketoacidosis. N Engl J Med 2001;344:264-9.

The authors reply:

To the Editor: Dr. Gebara raises several issues that merit responses. First, limiting the cerebral-edema group to patients with adverse outcomes would be relevant only if interventions for the treatment of cerebral edema were ineffective. Although there is limited information about therapy for cerebral edema in children with diabetic ketoacidosis, case reports suggest that prompt initiation of hyperosmolar therapy may be beneficial. ${ }^{1,2}$ We therefore cannot assume that the children who survived without sequelae had a less severe form of the disease than those who had adverse outcomes.

Second, although there are theoretical reasons why rapid administration of hypotonic fluids might contribute to cerebral edema, neither the rate of fluid administration nor the rate of sodium administration was significantly associated with cerebral edema in the patients we studied. In addition, in a subanalysis that we conducted, an interaction term combining the rates of fluid and sodium administration was not significantly associated with cerebral edema. We recommend that physicians caring for children with di- abetic ketoacidosis administer rehydration therapy to these patients at moderate rates and that isotonic fluids be used for the initial several hours.

Finally, we do not know whether children who had cerebral edema before in-hospital therapy for diabetic ketoacidosis ingested excess hypotonic fluid at home. Most children with severe diabetic ketoacidosis, however, have a history of persistent vomiting and present with gastrointestinal ileus. It is therefore unlikely that they could both ingest and absorb substantial quantities of fluid at the same time.

\section{Nicole Glaser, M.D. Nathan Kuppermann, M.D., M.P.H. University of California, Davis, School of Medicine Davis, CA 95616}

1. Franklin B, Liu J, Ginsberg-Fellner F. Cerebral edema and ophthalmoplegia reversed by mannitol in a new case of insulin-dependent diabetes mellitus. Pediatrics 1982;69:87-90.

2. Shabbir N, Oberfield SE, Corrales R, Kairam R, Levine LS. Recovery from symptomatic brain swelling in diabetic ketoacidosis. Clin Pediatr 1992;31:570-3.

\section{Case 4-2001: Acute Sarcoidosis}

To the Editor: The February 8 Case Record ${ }^{1}$ involves a patient with Löfgren's syndrome. In his discussion of the case, Dr. Bates does not sufficiently emphasize the importance of the recognition of periarticular ankle inflammation as a particular presenting sign of acute sarcoidosis. In the Nordic countries and Spain, Löfgren's syndrome is the most common form of the disease and frequently starts with periarticular ankle inflammation. In our series of 186 white patients with Löfgren's syndrome, 35 (19 percent) presented with periarticular ankle inflammation alone and 46 (25 percent) had periarticular ankle inflammation in association with erythema nodosum. ${ }^{2}$

Periarticular ankle inflammation is an acute inflammation of the tissues around the ankles without true arthritis. The typical lesions of erythema nodosum may be absent or may appear concomitantly with periarticular ankle inflammation, or a few days later. Arthrocentesis is ineffective, and biopsy of the inflamed skin shows nonspecific panniculitis. The accompanying clinical and radiologic findings and final outcome are so similar to those of classic Löfgren's syndrome that this condition is considered to be a variant of Löfgren's syndrome, even in the absence of erythema nodosum. ${ }^{3}$ The diagnosis of sarcoidosis should be strongly considered in patients who present with periarticular ankle inflammation, whether or not they have associated erythema nodosum, and a chest radiograph should be obtained to confirm the presence of bilateral hilar lymphadenopathy.

JUAN MAÑÁ, M.D. Carmen Gómez-Vaquero, M.D. Abelardo Montero, M.D. Ciutat Sanitària i Universitària de Bellvitge 08907 Barcelona, Spain

1. Case Records of the Massachusetts General Hospital (Case 4-2001). N Engl J Med 2001;344:443-9.

2. Mañá J, Gómez-Vaquero C, Montero A, et al. Löfgren's syndrome revisited: a study of 186 patients. Am J Med 1999;107:240-5.

3. Mañá J, Gómez-Vaquero C, Salazar A, Valverde J, Juanola X, Pujol R. 
Periarticular ankle sarcoidosis: a variant of Löfgren's syndrome. J Rheumatol 1996;23:874-7.

To the Editor: Dr. Bates appropriately cites Willan as providing the first description of erythema nodosum in the medical literature, in 1798. However, Leopold Mozart, Wolfgang's father, should receive some credit for his earlier and apt description of that syndrome. In a letter to his wife dated October 30, 1762, Leopold describes his ailing son in the following manner:

As he was going to bed, he complained a good deal of his backside and his hips. When he got into bed, I examined the places where he said he had pain and found a few spots as large as a kreutzer [a small Austrian coin], very red and slightly raised and painful to the touch. But they were only on his shins, on both elbows, and a few on his posterior; altogether there were very few. ${ }^{1}$

Leopold's description of the evolution of these lesions provides convincing evidence that he should share credit for documenting this important clinical syndrome.

Robert B. Howe, M.D. University of Minnesota Medical School Minneapolis, MN 55455

1. Anderson E. The letters of Mozart and his family. New York: Norton, 1985 .

The authors reply:

To the Editor: Mañá and colleagues appropriately emphasize the importance of symmetric periarticular ankle inflammation as a presenting sign of acute sarcoidosis. The distinction between this syndrome and symmetric polyarthritis is subtle but important. Both can provide important clues with respect to the onset of acute sarcoidosis.

Howe describes a fascinating historical reference to the early recognition of erythema nodosum. We were unaware of this citation, which predates Willan's description of erythema nodosum in the medical literature in 1798 . We doubt that Willan would mind sharing this distinction with Wolfgang Amadeus Mozart's father.

Peter Bates, M.D.

Maine Medical Center Portland, ME 04102

Eugene J. MARK, M.D.

Harvard Medical School Boston, MA 02115

\section{Review of The Adonis Complex}

To the Editor: We question the scientific basis for several statements in Handelsman's recent review of our book, The Adonis Complex (Jan. 11 issue). ${ }^{1}$ Handelsman dismisses anabolic-steroid-induced hypomanic syndrome (sometimes called "roid rage") as "street folklore" and "an excuse for bad behavior," a claim that contradicts the findings of three placebo-controlled, double-blind studies and numerous controlled field studies. ${ }^{2,3} \mathrm{He}$ also dismisses as "an un- substantiated claim" our suggestion that there is a natural limit to the muscularity that lean men can attain without steroids, despite the fact that our hypothesis is based on a peer-reviewed study of 157 athletes ${ }^{4}$ that has never, to our knowledge, been challenged in the subsequent literature. ${ }^{3}$ If Handelsman or others possess contrary evidence, we would urge them to publish it for scientific inspection.

Handelsman also implies that we have neglected the possibility that male body-image disorders might be "merely a variant of obsessive-compulsive disorder." Yet we propose precisely this hypothesis in our book and in our published scientific papers. ${ }^{5}$ More generally, Handelsman states that our book provides "no specific bibliography, making it hard to examine its scientific background." The Adonis Complex, however, cites more than 290 publications, including 200 peer-reviewed studies, more than 40 of which are from our own laboratories.

We also question the reviewer's characterization of our patients. Body-image disorders are recognized diagnostic entities that are sometimes associated with serious morbidity and even mortality. Calling these patients "pathetic men" with "narcissistic self-absorption" who are engaged in a "comic-book satire" trivializes their disabling and treatable psychiatric conditions.

Harrison G. Pope, JR., M.D. Roberto Olivardia, Ph.D.

Harvard Medical School Boston, MA 02115

Katharine A. Phillips, M.D. Brown School of Medicine Providence, RI 02905

1. Handelsman D. Review of: The Adonis complex: the secret crisis of male body obsession. N Engl J Med 2001;344:146-7.

2. Pope HG Jr, Kouri EM, Hudson JI. Effects of supraphysiologic doses of testosterone on mood and aggression in normal men: a randomized controlled trial. Arch Gen Psychiatry 2000;57:133-40.

3. Pope HG Jr, Brower KJ. Anabolic-androgenic steroid abuse. In: Sadock BJ, Sadock VA, eds. Kaplan \& Sadock's comprehensive textbook of psychiatry. Vol. 1. 7th ed. Philadelphia: Lippincott Williams \& Wilkins, 2000: 1085-95.

4. Kouri EM, Pope HG Jr, Katz DL, Oliva P. Fat-free mass index in users and nonusers of anabolic-androgenic steroids. Clin J Sport Med 1995;5:223-8.

5. Phillips KA, McElroy SL, Hudson JI, Pope HG Jr. Body dysmorphic disorder: an obsessive-compulsive spectrum disorder, a form of affective spectrum disorder, or both? J Clin Psychiatry 1995;56:Suppl 4:41-51.

\section{Dr. Handelsman replies:}

To the Editor: Reviewing a review starts a downward spiral. It is a meager defense against a critique of deficient scientific rigor in an approximately 300-page book to complain that a short review lacks scientific details. Whether scattering references among footnotes regardless of their quality constitutes a specific bibliography or not, it hinders the evaluation of the scientific validity of assertions - a task the book's popular approach often makes necessary. Semantic quibbles over how to describe the behavior of men enslaved by destructive obsessions do not warrant an argument.

The new law of nature on body composition that the authors claim to have discovered relies on evidence such as guessing body weight and height from fan-magazine photos. Does a $1.0-\mathrm{m}$-tall dwarf weighing $40 \mathrm{~kg}$ defy a law of nature or merely an extravagant claim? The onus of scientific proof is on the proponents and requires independent 